Karadeniz Uluslararası Bilimsel Dergi

Volume: 48, Winter-2020, p. (261-273)

ISSN: 1308-6200 DOI Number: https://doi.org/10.17498/kdeniz.804780

Research Article

Received: October 3, 2020 | Accepted: December 5, 2020

This article was checked by ithenticate.

\title{
ORHON YAZITLARINDA KISSI ADI VE UNVAN ÜZERİNE
}

\section{WRITING THE NAMES OF PEOPLE AND TITLES BASED ON ORHON'S WRITINGS}

\section{ОБ ИМЕНИ И ТИТУЛЕ ЧЕЛОВЕКА В ОРХОНСКИХ НАДПИСЯХ}

\section{Osman TÜRK*}

\section{ÖZ}

Eski Türkçenin temel kaynaklarını oluşturan Orhon yazıtları, XVIII. yüzyılın başlarında ilk olarak Sibirya'da tesadüf edilen ve bundan sonraki yıllar içerisinde Avrasya'nın farklı yerlerinde tespit edilen ve Eski Türkçenin ana kaynaklarını meydana getiren Köktürk yazıtları, XIX. yüzyılın sonuna doğru çözümlenmesiyle birçok bilginin de gün ışığına çıkmasını sağlamıştır. Türk dilinin takip edilebilen en eski yazılı belgelerinden olan Orhon Yazıtları; Türk edebiyatı, tarihi, kültürü ve sosyal yaşantısı hakkında bilgi veren yazıtlardır. Türklük biliminin bilimsel olarak kabul edilip ve yayılması temel olarak Moğolistan'da yer alan Göktürk yazıtların keşfi ile başlamıştır. Yazıtların çözümlenmesinden sonra Türk kültürü hakkındaki bilgilere varılmıştır. Bu yazılı belgeler özellikle Türk dilinin değerlerini ve yaşadığı dönemlerini belgeleme bakımından değerlidir. $\mathrm{Bu}$ sebeple yazıtların keşfedilişinden günümüze kadar yazıtlarla ile ilgili yüzlerce çalışma yapılmıştır. Çalışmada, Orhon yazıtlarında yer alan kişi adı ve unvanlar incelenmeye alınmıştır. Yapılan araştırma, Orhon yazıtlarından (Köl Tegin, Bilge Kağan, Tonyukuk, Ongi, Küli Çor) oluşmaktadır. Çalışmada, yaklaşık olarak bin üç yüz yıllık tarihi derinliği olan yazıtlardaki söz varlığının ortak unsurlarını incelenmiştir. Böylece Türk dilinin ilk yazılı örneklerinden yola çıkarak eserde kullanılan kişi adı, unvan ve unvan niteleyicilerin kullanımına dair cümle içerisinde tespiti yapılıp ve bu örnekler belirtilmeye çalışılmıştır. Temel kaynak olarak Prof. Dr. Erhan Aydın'ın Orhon Yazıtları kitabı esas alınarak bu çalışma yapılmıştır.

Anahtar kelimeler: Türkoloji, Köktürkçe, Orhon yazıtları, Eski Türkçe, Unvan, Kişi adı.

\begin{abstract}
Orhon inscriptions, which constitute the basic sources of Old Turkish, XVIII. Köktürk inscriptions, which were first coincided in Siberia at the beginning of the century and determined in different parts of Eurasia in the following years and formed the main sources of Old Turkish, XIX. With the analysis towards the end of the century, a lot of information
\end{abstract}

\footnotetext{
* ORCID: 0000-0002-9379-6225 Dr. Öğr. Üyesi, Harran Üniversitesi, Fen Edebiyat Fakültesi, Türk Dili ve Edebiyatı Bölümü, osmanturkgau@gmail.com
} 


\section{Orhon Yazıtlarında Kişi Adı ve Unvan Üzerine}

was brought to light. Orhon Inscriptions, one of the oldest written documents of the Turkish language, are inscriptions that provide information about Turkish literature, history, culture and social life. Scientific acceptance and dissemination of the science of Turkishness began with the discovery of the Göktürk inscriptions in Mongolia. After analyzing the inscriptions, information about Turkish culture was reached. These written documents are especially valuable in terms of documenting the values of the Turkish language and the periods in which it lived. For this reason, hundreds of studies have been carried out about the stones since the discovery of the inscriptions. In the study, the names and titles of the Orhon inscriptions were examined. The research consists of Orhon inscriptions (Köl Tegin, Bilge Kağan, Tonyukuk, Ongi, Küli Çor). In the study, the common elements of vocabulary in inscriptions with a historical depth of approximately one thousand three hundred years will be examined. Thus, by using the first written examples of the Turkish language, the use of the names and titles used in the work was determined by analyzing them in the sentence. Professor as the main source Dr. This study was conducted based on Erhan Aydın's book titled Orhon Inscriptions

Keywords: Turcology, Köktürk, Orhon inscriptions, Old Turkish, Title, Person name.

\section{АННОТАЦИЯ}

Орхонские надписи, составляющие основные источники древнетюркского XVIII в. Надписи Köktürk, которые впервые совпали в Сибири в начале века, а в последующие годы были определены в разных частях Евразии и составили основные источники древнетюркского языка XIX в. В ходе анализа, проведенного ближе к концу века, было обнаружено много информации. Орхонские надписи, один из старейших письменных документов на турецком языке, которому можно следовать; Это надписи, которые дают информацию о турецкой литературе, истории, культуре и общественной жизни. Научное признание и распространение науки о тюркском языке в основном началось с открытия надписей Göktürk в Монголии. После анализа надписей были получены сведения о турецкой культуре. Эти письменные документы особенно ценны с точки зрения документирования ценностей турецкого языка и периодов, в которые он жил. По этой причине с момента открытия надписей до сегодняшнего дня были проведены сотни исследований надписей. В ходе исследования были изучены имя человека и титулы в надписях Орхона. Проведенное исследование состоит из орхонских надписей (Köl Tegin, Bilge Kaan, Tonyukuk, Ongi, Küli or). В ходе исследования были изучены общие элементы словарного запаса в надписях с исторической глубиной примерно одна тысяча триста лет. Таким образом, на основе первых письменных примеров турецкого языка имя человека, титул и титул, использованные в произведении, были определены и указаны в предложении об использовании квалификаторов. Проф. Доктор Это исследование было проведено на основе книги Эрхана Айдына «Орхонские надписи».

Ключевые Слова: Тюркология, Коктюрк, Орхонские надписи, древнетюркский, титул, имя.

\section{Giriş}

Unvan kavramı, Arapçadan dilimize geçmiştir. Kubbealtı sözlükte (2011) şöyle geçmektedir; 1. Bir kimsenin pâyesini gösteren veya durumunu, memuriyet 
rütbesini, görevini belirten söz, lakap. 2. Bir kitabın veya bir bölümünün, makale, mektup ve benzerinin başına yazılan yazı veya kelime. 3. İftihar, şan, şöhret. Türkçe sözlükte (2005: 2036) Bir kimsenin mesleği, işi, görevi veya toplum içindeki durumu ile ilgili olarak kullanılan ad, san olarak ele almış. Bir kitap veya makalenin başına yazılan yazı, ser-levha; bir kimsenin adı, sanı, kimliği ve şöhreti (Parlatır, 2006: 1753). İsim yani ad; herhangi bir anlam için konulmuş bir söz; bir kavramı zihne taşıyan söz, fiil veya nitelik türünde semboller olarak karşımıza çıkar (Çelebi, 1998: 195). Unvan ise, bir kimsenin memuriyet rütbesini ve görevini belirten söz yani lakaptır (Özaydın, 2012: 163). Kişilere atfedilen unvanlar ulusların yaşam biçimlerini yansıtır. Bir sosyal yapı içerisinde icra edilen unvan ve bu unvanlara verilen öneme bakılarak o toplumun kültürel değerleri hakkında düşünce sahibi olunabilir (Şen, 2007: III).

Köktürk yazıtları (Köl Tegin, Bilge Kağan, Bilge Tonyukuk), Bumin önderliğinde Avarların hâkimiyetine son verip Türk Kağanlığının temsilcisi olarak 552 yılında iş başına geçen Köktürk Devleti'nin II. döneminde meydana getirilmiş mezar taşlarıdır. Orhun yazıtları; Türk edebiyatı, kültürü, tarihi ve sosyal yaşantısı hakkında bilgi veren yazılı taşların yansıra, Türk dilinin takip edilebilen en eski yazılı belgelerindendir. Türklük biliminin bilimsel olarak ilgi görüp yayılması temel olarak Moğolistan'da bulunan Göktürk yazıtların keşfi ile başlamıştır. Yazıtların çözümlenmesinden sonra Türk kültürü hakkındaki bilgilere varılmıştır. $\mathrm{Bu}$ yazılı belgeler bilhassa Türk dilinin değerlerini ve yaşadığı dönemleri göstermesi bakımından büyük bir öneme haizdir.

Yenisey yazıtları olarak bilinen yazıtların büyük çoğunluğu Yukarı Yenisey Vadisi'nde, doğuda Tuva'nın başkenti Kızıl'dan 60 kilometrelik uzaklıkta bulunan Sargal-Aksı'dan başlayarak batıda Hemçik Irmağı yakınındaki Şançi kırlarına kadar 200 kilometrelik uzaklıkta yer almaktadır (Kormuşin 2001: 259; Aydın, 2011: 6) Yenisey yazıtları, Moğolistan'ın kuzeyinde, Yenisey Irmağ boyunca, hangi boylarca dikildiği çok belli olmamakla birlikte daha çok Kırgızlar tarafından dikildiği kabul edilen ve bugün toplam sayısı 200'ü aşan yazıtlardır (Aydın, 2017: 49). Yazıtlar, 1889 yılında Moğolistan'da Orhun Vadisi'nde bulunmuşlardır. Bu yazıtlar II. Göktürk Kağanlığına aittir. Yazılış tarihleri MS. 8. yüzyılın başlarına dayanan ve Türkçenin elimizde bulunan en eski yazıtlardır (Orkun, 1994: 18; Aksan, 2018: 88). Yazitlardan Köl Tigin yazıtı 732 yılında, Bilge Kağan yazıtı 735 yılında yazılmışlardır (Ergin, 2006). Türk runik alfabe ile yazılmış eski Türk yazıtlarından ilk bahseden Alaaddin Melik Cüveyni'nin Tarih-i Cihan-güşa eseridir (Aydın, 2018: 25). Yenisey yazıtlarıyla ilgili Türkiye'de ilk metin yayımı çalışması Hüseyin Namık Orkun'a aittir (Aydın, 2019: 21)

13. yüzyılın ortalarında yazıtlar bulunmuşsa da yazıtların okunup çözümlenmesi 19. yüzyılın sonlarında Danimarkalı dilci V. Thomsen Orhun Yazıtlarında tarafından gerçekleştirilmiştir. Thomsen, 1893'teki Kopenhag'daki Danimarka Kraliyet İlimler Akademisi toplantısında Orhun yazitlarını çözümlediğini dünyaya duyurmuştur. Orhun Yazıtlarının Türkiye'ye tanıtılması ise ancak dört yıl sonra, 1897 yılında gerçekleşmiştir. 1897'deki Müsteşrikler Kongresinde Thomsen'i tanıyan Ahmet Mithat Efendi, onun kitabından bir nüsha 


\section{Orhon Yazıtlarında Kişi Adı ve Unvan Üzerine}

alarak İstanbul'a dönmüş ve eseri Necip Asım'a vermiştir. Thomsen'in eserinin giriş kısmından faydalanan Necip Asım, 1897'de Pek Eski Türk Yazısı adıyla eseri neşrederek Orhun yazıtlarını bizde ilk kez tanıtmış olur (Orkun, 1986; Ercilasun, 2004: 156) Orhun Yazıtları taşıdığı edebi değerin yanında dil olarak da oldukça önemli bir yere sahiptir. Türk dilinin yazılı ilk örneği olmasına rağmen yazıtlarda kullanılan dilin işlek bir dil olduğu ifade edilmiştir (Caferoğlu, 1984:110) Devletin ortaya çıktığı coğrafya ve kağanlar başta olmak üzere devlet yöneticilerinin milleti mutlu ve devleti güçlü k1lmak için töre hükümlerini uygulayarak devleti yönetmeleridir. Devlet yönetiminde törenin değişmez hükümleri olan könilik (adalet), uzluk (faydalılık), tüzlük (eşitlik) ve kişilik (evrensellik) ön plana ç1kmışt1. (Kafesoğlu, 1989: 235; Durmuş, 2019: 31). Türk kültür teşkilatında devlet meclisine "toy" adı veriliyordu. "Toy"a katılanlar ise "Toygun" adiyla anılıyordu. "Toygun”, "toy üyesi” anlamında kullanılmıştı. Toy üyeleri Tigin, Kül Çor, Apa, Erkin, Yen-hung-ta, Tudun, İl-teber, Tarhan vb. unvanlar taşımaktaydılar. Bu unvanları taşıyanlar askeri- sivil idare sahipleri olarak devlet meclisine katılan kimselerdi (Kafesoğlu, 1989, 248-50; Durmuş, 2019: 32). Bilge Kağan, Köl Tegin ve Tonyukuk ağzından Türk milletinin o dönemde farklı ulus ve kavimlerle yaptıkları mücadelelerin ve yapılan mücadelelerin anlatıldığı, Türk milletinin bekası adına birtakım ikazlar içeren, Türk devlet düzeni, hükümdarlık anlayışı, askeri geleneği, Türk tarihi, kültürü ve sosyal yapısı hakkında birtakım bilgi ve belgelere ulaşmamızı sağlayan Orhun yazıtları hitabet niteliğinde yazılmış metinlerdir (Aly1lmaz, 1996, Orkun, 1986, Ergin, 2006, Tekin, 2006; Batur ve Yildirım 2013).

\section{Bulgular}

alp alp, kahraman, yiğit; güç, zor. edgü bilge kişig edgü alp kişig yorıtmaz ermiş bir kişi.... (KT G 6)

alpagu kahraman(lar). ...agıtıp toñra bir uğuş alpagu on er erig toña t'egin yogınta eğirip... (KT K 7)

alp salçi Köl Tegin'in atını kullandığı kişi veya atın adı. ...ulug süniş̧ 1 süñ̈u̧smiş alp salçi ak altın binip tegmiş...(KT D 40)

apa ata, ced; bir unvan niteleyicisi.

...başlayu ulayu şadapıt begler öñre tölis begler apa tarkan (BK G 13)

apa tarkan yüksek bir unvan.

... apa tarkangaru içre saw ıdmış bilge toñukuk añıg ol üz ol (T 34)

aşok soğdluların lideri.

anta berüki aşok? Başllg sogdak bodun kop kelti... (T 46) 
at (I) ad, unvan.

bars beg erti kă̆an at bunta biz bértimiz sinilim...(KT D 20)

ataman tarkan kişi adı ve unvanı.

başlayu ulayu şad [apıt] begler <... > ataman tarkan tonyukuk boyla (BK G 14)

atlig (I) unvanl1.

kelti tép ög[irip sewinti] < .. > ka at bértim kiçig atligıg (BK D 41)

ayguçı sözcü, danışman.

yorıyur ermiş kaganı alp ermiş ayguçısı bilge ermiş ol... (T 10)

aymaglıg denilen, unvanlı?

Tamgan tarkan aymaglig béş yétmiş éçim atım <...> (O 4)

baga bir unvan.

...ök kagan kışdım bilge toñukuk boyla baga tarkan (T 6)

baga teñriken kişi adı ve unvanı.

kañım baga teñriken yen anta yorımış işig küçin bérmiş erti <... b. (O 5)

bars kişi ad1.

...suw [idi]siz kalmazun [téyi]n [az bodunug étip yaratıp $<\ldots>$ bars beg] (BK D 16)

başlayu ilk önce, evvela; baş, lider olmak.

... başlayu kırkız kaganıg [balbal tikdim] tür ük bodun atı küsi... (BK D 20)

başlıg mağrur; lider.

...bodunug kop almış kop baz kılmış başlıgıg yüküuntürmiş tizlig...(KT D 2)

baz kagan Dokuz Oğuzların kağan1.

... baz kagan tokuz oguz bodun yagı ermiş kırkız...( KT D 14)

bedizçi süsleme ustas1.

...bedizçi kelürtüm bedizet $<d>$ im ...( KT G 11)

beg bey.

bars beg erti kagan at ...( KT D 20)

beglik bey olmaya layık.

... ıdmış tawgaç bodunka beglik urı ...( KT D 7) 


\section{Orhon Yazıtlarında Kişi Adı ve Unvan Üzerine}

bilge bilge, hakim; unvan niteleyicisi.

... olorur ermiş bilge kagan ermiş alp kagan ermiş ...( KT D 3)

bilge ışwara tamgan tarkan kişi adı ve unvanı.

... yawgu inisi bilge ışwara tamgan tarkan aymaglı...( $\mathbf{O} 4)$

bilge toñukuk kişi adı ve unvanı.

... bilge toñukuk ben özüm tawgaç éline ...(T 1)

bitig taş étgüçi yazıt ustası.

... bediz yaratıgma bitig taş étgüçi tawgaç kagan ...(KT K 13)

boyla bir unvan.

$<\ldots>$ bo]yla tarka $[n]<\ldots>$ “< $<>$ Boyla Tarkan $<\ldots>$ " $($ KT Kap. b, $)$

boyla tarkan unvan grubu.

$<\ldots>[$ bo]yla tarka $[n]<\ldots>$ "< $<>$ Boyla Tarkan $<\ldots>$ " $($ KT Kap. b, $)$

böğü kagan Kapgan Kağan’ın kağanlık unvanlarından biri.

... basıtma témiş bög< < $>$ kagan bañaru ...( T 34)

böke yiğit savaşç1.

...bilgesi çawışı erti alpı bökesi erti (KÇ 17)

bukug kişi adı.

... ay yeti otuzka yog ertürtüm bukug totok...(BK G 10)

bumın kagan I. Türk Kağanlığının kurucusu. (Çin. Tumen ).

... eçüm apam bumın kagan istemi kagan olormıs ...(BK D 3)

buyruk komutan.

... bilge kagan ermiş alp kagan ermiş buyrukı bilge ermiş ...(BK D 4)

çaça señün kişi adı ve unvanı. < Çin. shazha jiangjun.

... süledim çaça señün sekiz tümen sü birle... (BK D 26)

çañ señün kiși adı ve unvanı. < Çin. Zhang jiangiun.

... tawgaç kagan çıkanı çañ señün kelti (KT K 13)

çawış yüksek bir askeri unvan.

... bilgesi çawışı erti alpı bökesi erti (KÇ 17)

çıkan yeğen; bir unvan.

... apa tarkan çıkan tonyukuk atıg... (KÇ 1) 
çıkan tonyukuk kişi adı ve unvanı.

... apa tarkan çıkan tonyukuk atıg... (KÇ 1)

çor bir boy.

... körti ulug küuli çor sekiz on yaşap... (KÇ 3)

er at erlik unvanı.

... inim köl tégin er at bultı altı yegermi... (KT D 31)

erdem erdem, kahramanlik, cesaret.

... alpı erdemi anta kükdi türk bodunka... (KÇ 4)

eren adam(lar), asker(ler).

... binip tokuz eren sançdı ordog... (KT K 9)

eșim kiși ad1.

...eşimig $\imath d m \imath s ̧$ saw ança $\imath d m \imath$ ş... (T 9)

él çor tégin kişi adı ve unvanı.

...kagan inişi él çor tégin kalıp ulayu... (KÇ 24)

él étmiş yawgu kişi adı ve unvanı.

... él étmiş yawgu oglı ışwara tamgan çor yawgu... (O 4)

élbilge katun Elteriş Kağan'ın eşi, Bilge Kağan'ın annesi.

...ögüm élbilge katun... (BK D 10)

éltewer yüksek bir unvan, boy lideri.

...agdı uygur éltewer yüzce erin... (BK D 37)

érkin bir unvan.

... özi kelti sir érkin ogll yeğen çor kelti (KÇ 21)

Idok kut boy lideri.

... yaşıma basmıl ıdok $<k>$ ut uguşum bodun $<$ um $>$ erti... (BK D 25)

Inançu bir unvan niteleyicisi.

...ınançu apa yargan tarkan atıg... ( KT B)

Inançu apa yargan tarkan kişi adı ve unvanı.

...ınançu apa yargan tarkan atıg... ( KT B)

Işwara yüksek bir unvan. < Skr. 1svara 
Orhon Yazıtlarında Kişi Adı ve Unvan Üzerine

ölti ekinti ıswara yamtar boz atıg binip..

(KT D 33)

ışwara bilge küli çor kişi adı ve unvanı.

... ışwara bilge küuli çor kişi... ( KÇ 8)

ışwara çıkan küli çor kişi adı ve unvanı.

... ışwara çıkan küli çor bolmış... (KÇ 2)

Işwara tamgan çor yawgu kişi adı ve unvanı.

... oglı ışwara tamgan çor yawgu inişi... (O 4)

ışwara tarkan kişi adı ve unvanı.

Işwar[a] tarkan balbalı (O Balbal)

Işwar yamtar kişi adı ve unvanı.

... ékinti ışwara yamtar boz atıg binip... (KT D 33)

iç buyruk bir unvan.

... iç buyruk sewig köl érkin başlayu... (BK G 14)

inel kagan II. Türk Kağanlığı'nın 3. kağanı. (Çin.Fuju)

... sü başı inal kagan tarduş şad... (T 31)

işiyi likeñ kişi adı ve unvanı. < Çin. sheren luxiang

... işiyi likeñ kelti bir tümen agı... (KT K 12)

kagan kağan.

... taş étgüçi tawgaç kagan çıkanı... (KT K 13

kaganla-kağanlı duruma getirmek.

... kaganladok kaganın yitürü ıdmış tawgaç... (KT D 7)

kaganlıg kağanı olan.

...ermiş kaganlıg bodun ertim kağanım... (KT D 9)

kagansıra-kağanını kaybetmek.

... kagansıramış bodunug küñedmiş kuladmış... (BK D 11)

kagansırat-kağanını elinden almak.

... kă̆anlıgıg kagansıratmış yagıg baz kılmış... (BK D 13)

kañ baba.

kañı lisün tay señün başadu... (BK G 11) 
kapgan kagan II. Türk Kağanlığı'nın ikinci kağanı.

kapgan kagan yéti otuz... (T 51)

katun kağanın karısı.

umay teg ögüm katun... (KT D 31)

koşu totok kişi adı ve unvanı.

... birle koşu totok birle... (KT K 1)

köl tégin II Türk Kağanlığının 4. Kağanı Bilge Kağan'ın kardeşi.

... üze olortum inim köl téginbirle sözleşdimiz... (KT D 26)

ku kişi adı.

... tawgaçgaru kunı señ்̈nüg ıdmış kıtañgaru... (T 9)

kunçuy prenses. < Çin. gongzhu

... k kunçuyug bértemiz özi yañnlttı kaganı ölti... (KT D 20)

küçlüg kagan kişi adı ve unvanı.

... küçlüg kagan yağımız boltı ol üç kagan... (T 20)

külli çor kişi adı ve unvanı.

... tarduş begler kül <i> çor başlayu ulayu... (BK G 13)

lisün tay señün kişi adı ve unvanı. $<$ Çin liguan dajiangjun

... lisün tay señün başadu béş yüzeren... (BK G 11)

markaraç tamgaçı kişi adı ve unvanı. < Skr. maharaja.

... makaraç tamgaçı oguz bilge tamgaçı kelti... (KT K 13)

nek señün kiși adı ve unvanı.

... bodunta nek señün ogul tarkan kelti (KT K 12)

ogul tarkan kişi adı ve unvanı.

... bodunta nek señün ogul tarkan kelti (KT K 12)

oguz bilge tamgaçı kişi adı ve unvanı.

... makaraç tamgaçı oguz bilge tamgaçı kelti... (KT K 13)

oñ kişi adı ve unvanı.

... buzdumuz tawgaç oñ totok béş... (KT D 31)

sagır çulug kişi adı ve unvanı.

... sagır çulugun yagıt $<d>\underline{\text { okd }}$ a... (KÇ 5) 
señün general < Çin. jiangjun.

udar señün kelti tawgaç kaganta işiyi... (KT K 12)

sewig köl érkin kişi adı ve unvanı.

... sewig köl érkin başlayu ulayu... (BK G 14)

silig kişi adı?

... silig begiñ kedimlig torug at binip tegdi... (KT D 33)

sir érkin kişi adı ve unvanı.

... éltewer özi kelti sir érkin oğlı... (KÇ 21)

şad yüksek bir unvan.

... şadın anta ölürtüm elin anta élin... (BK D 28)

tadık çor kiși adı ve unvanı.

... e $\tilde{\boldsymbol{n}}$ ilki tadıkiñ çorun boz... (KT D 32)

tamgan kişi adi.

... tamgan çor yawgu inisi bilge... (O 4)

tarduş ınançu çor kişi adı ve unvanı.

... kaganta tarduş ınançu çor kelti bark... (KT K 13)

tarkan yüksek bir unvan.

... begler öñre tölis begler apa tarkan (BK G 13)

tarkat tarkanlar.

... şadapıt begler yırka tarkat buyruk... (KT G 1)

tawgaçı Çin'e gönül vermiş (kişi)

... tutupan tawgaç kaganka (KT D 7)

teñriken aziz, kutlu, hazretleri.

... baga teñriken yen anta yorımış... (O 5)

teñriteg aziz kutlu

... teñnriteg teñnride bolmış türük bilge kagan... (KT G 1)

teñriteg teñri yaratmış türük bilge kagan Bilge Kağan'ın oğlu Tengri Kağan'ın (Çin. Dengli) kağanlık unvanı.

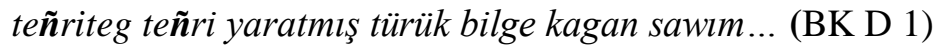


teñriteg teñride bolmış türük bilge kagan II. Türk kağanlığının dördüncü kağanı Bilge Kağan'ın kağanlık unvanı.

... teñnriteg teñnide bolmuş türük bilge kagan bo ödke olortum... (KT G 1)

tégin prens

...bo bitig bitigme atıs1 yol< < > ug tégin bitidim (KT G 13)

toña tégin kişi adı ve unvanı.

... on erig toña tégin yogınta egirip... (KT K7)

toñukuk kişi adi.

... bilge toñukuk ben özüm tawgaç...(T 1)

t. T 1 (tonyukuk)

tonyukuk buyla baga tarkan kişia adı ve unvanı.

... ataman tonyukuk buyla baga tarkan ulayu (BK G 14)

toygun éltwer kişi adı ve unvanı.

... bunça bedizçig toygun éltwer kel[ürti] (KT K-D)

toygut kişi adi.

... aylgma toygut bo $<\ldots>$ begim... (KT G-B)

türük bilge kağan Bilge Kağan'ın kağanlık unvanlarından biri.

... türük bilge kagan [ay]ukl[na] inim köl... (KT B)

udar señün kişi adı ve unvanı.

udar sẽ̃ün kelti tawgaç kaganta işiyi... (KT K 12)

uluğ érkin kişi adı ve unvanı.

...bayırku ulŭg érkin yagı boltı anı... (KT D 34)

yalawaç elçi

... tatawı bodun tawgaç kaganka körti yalawaçı edgü sawı... (BK D 39)

yamı kagan Bumın Kağan.

eçümüz apamız yamı kagan tört... (O 1)

yargan bir unvan.

... ançu apa yargan tarkan atıg... (KT B)

yawgu kağandan sonraki büyük unvanlardan biri.

... étmiş yaygug şadıg anta bérmiş... (BK D 12) 


\section{Orhon Yazıtlarında Kişi Adı ve Unvan Üzerine}

yégen bir unvan.

...üçünç yégen silig begiñ kedimlig... (KT D 33)

yégen çor kişi adı ve unvanı.

... özi kelti sir érkin oglı yégen çor kelti (KÇ 21)

yégen silig beg kişi adı ve unvanı.

...üçünç yégen silig begiñ kedimlig... (KT D 33)

yérçi k1lavuz.

...yorısar yaramaçı tedim yerçi tiledlim (T 23)

yollug tégin Köl Tegin ve Bilge Kağan yazıtlarını yazdıran kişi.

... bo bitig bitigme atısı yol $<l>$ ug tégin bitidim (KT G 13)

yurç kayınbirader

... yurçın yaraglig eliğin tutdı... (KT D 32)

\section{Sonuç}

Orhon yazıtları (Köl Tegin, Bilge Kağan, Tonyukuk, Ongi ve Kulli Çor) Türk kültür tarihi açısından çok önemli birer belge niteliğindedir. Türk dili ve kültürünü günümüze taşımasında büyük katkılar sağlamış olan yazıtlar, dönem itibarıyla sosyal, askeri ve devlet teşkilatlanması açısından bilgiler sunmuştur. Kişilere verilen unvanları bağlamında düşünüldüğünde sahip olunan unvanın, kişinin toplum içindeki yerini göstermesi, haliyle statüsünün belirlenmesi açısından önem arz etmektedir. Türklerin tarihî kaynaklarında unvanların varlı̆̆1 saptanabilmekte ve büyük bir çeşitlilik sergilemektedir. Devlet yöneticilerinin sahip olması gereken iletişim özellikleri anlamında bakıldığında da ciddi uyarıları ve önerileri olmuştur. Dokuz Oğuz beyleri milleti bu sözümü iyice işit adamakıllı dinle sözü, yazıtın aynı zamanda hitabet olarak kayda geçtiği Türk dilinin sanatsal zevkinin olduğunun ispatıdır. Yaşadığı tecrübeleri ileriki yaşama yönelik tespitleri bilgeliğin önemli işaretleridir. Bu bağlamda bakıldığında "bilge ve bilgelik" unvanı hakkıyla taşımak için gözü pek, kahraman, cesur, yürekli, zeki, uyanık, hoşgörülü, saygılı, adil ve adaletli gibi birçok özelliği barındırmış devlet yöneticileri varlı̆̆ sayesinde bugünlere derin izler bırakmıştır. Devletini her türlü iç ve dış tehditlere karşı iyi yönetmiş, hamleleri iyi belirlemiş ve bilgelikleriyle işin üstesinden gelmeyi başarmıştır. Başka bir deyişle unvanların gelişigüzel verilmediği, bir takım özelliklere haiz olması gerektiği en önemli unsurdur. Devlet yöneticilerin stratejileri belirlemede bilge kişilerin varlığg her dönemde var olması ülke ve millet için önemlidir. Bu çalışmada 114 unvan ve kişi ismi tespit edilmiştir. Bunların içerisinde "alp" "bilge”, "yérçi-kılavuz", "teñriken-aziz, kutlu, hazretleri" unvanları hak eden kişilere atfetmiştir. Tüm bu tespitler yazıtların kişilere verilen unvanların anlam ve mahiyetini ortaya çıkartmıştır. 


\section{Kaynakça}

Aksan, D. (2018). Türkçenin Söz Varlı̆̆ı. Ankara: Bilgi Yayınevi.

Alyılmaz, C. (1996). Köktürk Yazıtları Ve Köktürk Yazıtlarında Atlar. Türkiyat Araştırmaları Enstitüsü Dergisi, 4, ss. 155-163.

Aydın, E. (2011). Yenisey Yazıtlarında Geçen Unvanlar Ve Unvan Niteleyicileri. Türk Dil Kurumu Belleten. 2, 5-26.

Aydın, E. (2017). Türkiye Söz Varlı̆̆ı Açısından Yenisey Yazıtlarının Moğolistan Yazıtlarından Farklılıkları Üzerine Notlar. Uluslararası Türk Lehçe Araştırmaları Dergisi (TÜRKLAD) Cilt 1, Sayı 1, S. 48-58.

Aydın, E. (2018). Orhon Yazıtları. İstanbul: Bilge Yayınevi.

Aydın, E. (2019). Sibirya'da Türk izleri. İstanbul: Kronik Yayınevi.

Ayverdi, İ. (2005) Kubbealtı Lugatı Misalli Büyük Türkçe Sözlük. Kubbealtı. İstanbul: Neşriyat Yayınevi.

Batur. Z. ve Yildırım, G. (2013). Orhun Yazıtlarında Anlama Ve Anlatma Becerileri. Turk1sh Studies. 8/4, ss. 313-333.

Çelebi, İ. (1998). Klasik Bir Kelâm Problemi Olarak İsim-Müsemmâ Meselesi”, ILAM Araştırma Dergisi, C. III, S.1, ss.103-114

Caferoğlu, A. (1984). Türk Dili Tarihi. İstanbul: Enderun Yayınları

Durmuş, İ. (2019) Bilge Tonyukuk. Asya Araştırmaları Dergisi, 3/1, ss. 2667-6419

Ercilasun, A. B. (2004). Türk Dili Tarihi. Ankara: Akçağ Yayınları

Ergin, M. (2002). Orhun Abideleri. İstanbul: Boğaziçi Yayınları.

Ergin, M. (1993) Türk Dil Bilgisi. İstanbul: Bayrak Yayınları

Kafesoğlu, İ. (1989). Türk Milli Kültürü. İstanbul: Boğaziçi Yayınları.

Orkun, H. N. (1986). Eski Türk Yazıtları. Ankara: TDK Yayınları.

Özaydın, A. (2012). Unvan. DİA, XLI, İstanbul: TDV Yayınlar1. ss.163-166.

Parlatır, İ. (2006). Osmanlı Türkçe Sözlük. Ankara: Yarg1 Yayınevi

Şen, S. (2007). Orhon, Uygur ve Karahanlı Metinlerindeki Meslekler Bağlamında Eski Türk Kültürü. Yayımlanmamış Doktora Tezi, Samsun: Ondokuz Mayıs Üniversitesi Sosyal Bilimler Enstitüsü.

Tekin, T. (2006). Orhon Yazıtları. Ankara: TDK Yayınları

Türkçe Sözlük (2005). Ankara: Türk Dil Kurumu. 